\title{
Antibiotics as Microbial Secondary Metabolites: Production and Application
}

\author{
Hassan, M. Awad ${ }^{a, b^{*}}$, Kamal, Y. I. EL-Shahed ${ }^{b}$, Ramlan Aziz $^{a}$, Mohamed Roji Sarmidi ${ }^{a}$, Hesham, A. El-Enshasy ${ }^{a, c}$ \\ ${ }^{a}$ Institute of Bioproduct Development, UniversitiTeknologi Malaysia, 81310 UTM Joho Bahru, Johor, Malaysia \\ ${ }^{b}$ Chemistry of Natural and Microbial Products Department, National Research Centre (NRC), Dokki, Cairo, Egypt \\ ${ }^{c}$ Bioprocess Development Dept., Genetic Eng. and Biotechnol. Res. Inst., City for Scientific Research, New Burg Al-Arab, 21934 Alexandria, Egypt
}

*Corresponding author: hassan@ibd.utm.my

\section{Article history}

Received :1 August 2012

Received in revised form :7 Sept.

2012

Accepted :1 October 2012

\section{Graphical abstract}

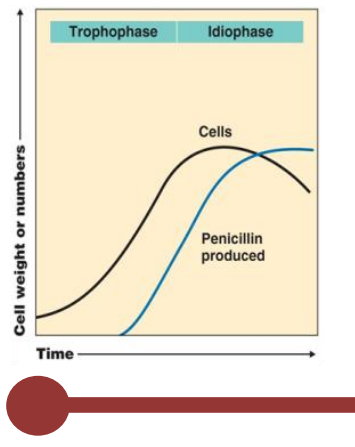

\subsection{INTRODUCTION}

Currently, the appearance of multiple antibiotic resistant pathogenic bacteria is increasing, compromising the clinical treatment of a growing number of infectious diseases. There is thus an urgent need for new drugs effective against current antibiotic resisting pathogens and opportunistic pathogens. However, during the last 20 years, no new compounds have been introduced into the clinical practice $[1,2]$. New bacterial or fungal strains are sometimes discovered through soil and water samples and this has led to an impressive archive of antibacterial agents [3].

Penicillin, a type of fungal metabolite, declared the beginning of the antibiotics' golden age as it had motivated more investigations to be done on hundreds of microbial metabolites to control bacterial diseases. This eventually evolved into the control of fungal infections, parasitic infestations and some carcinogenic agents. As the history's most studied secondary metabolite, antibiotics have profound medical relevance and have also been applied in many industrial, agricultural, and forest applications [4].

The antibiotic era began in 1929 with the penicillin discovery by Fleming. However, antibiotic research and industry only flourished after the commercial production of penicillin in the 1940s [5,6]. Ironically, until the 1970s, only penicillins and cephalosporins were the two known natural $\beta$ lactam antibiotics. The identification of other $\beta$-lactamcontaining molecules and antibiotics was only possible after new screening and isolation techniques were invented [7]. In fact, screening of microorganisms for the production of antibiotics has provided the cornerstone of antibiotic research programs for the past thirty years. These programs were mostly carried out using fungi and actinomycetes as they can produce natural products with a wide range of chemical structures. To date, more than 400 peptides with antimicrobial activities have been discovered from various sources such as plants, insects, bacteria, and vertebrates.

Two main strategies have been used during the screening process of antibiotics. The first strategy screens out the secondary metabolites known to be useless antibiotics and the second strategy screens for unknown compounds that have demonstrated inhibiting characteristics on some enzymes and/or biological activities of some targets. The latter is mostly done using new technologies. The best antitumor substances are mithramycin, bleomycin, daunomycin and adriamycin [6]. Some antibiotics, on the other hand, have properties similar to 
anesthetics, anticoagulant, anti-inflammatory, and immunosuppressant. Others may show anabolic, hemolytic, hypocholesterolemic, and vasodilation effects.

The four most important groups of antibiotics, notably penicillins, cephalosporins, tetracyclines and erythromycin take up about US $\$ 4.2$ billion global bulk sales per annum. Table 1 illustrates the blockbuster markets for antibiotics. Goodman,[9] presented the status of non-medical uses of antibiotics, revealing its past, present, and potential contribution to food and agriculture. Antibiotics have also been used by microbiologists to solve some problems in the research laboratory.

Table 1 Chartbuster markets for antibiotics

\begin{tabular}{ll}
\hline Product & \$ billion \\
\hline Cephalosporins & 10 \\
Lipitor & 9.2 \\
Zocor & 6.2 \\
Penicillins & 6 \\
Augmentin & 2 \\
Azithromycin & 1.5 \\
Clarithromycin & 1.2 \\
Rocephin & 1.1
\end{tabular}

Clavulanic acid (CA): $\beta$-Lactamase inhibitor. The market is over $\$ 1$ billion. Used in combination with susceptible penicillins. The combination of $\mathrm{CA}+$ amoxicillin $=$ Augmentin $^{\mathrm{tm}}$ and the added of $\mathrm{CA}+$ ticarcillin Timentin $^{\text {tm }}$ (White et al., [62]
An interesting property common to most potent antibiotics is that at very low concentrations, they act as growth stimulants [4]. Actinomycetes produce about $75 \%$ of all described antibiotics. Streptomyces species make $75 \%$ of all actinomycetes secondary metabolites. The amount of secondary metabolites produced by the Streptomyces hygroscopicus strains is over 180 [10-12]. Table 2 depicts the number of bioactive microbial secondary metabolites divided into two main groupsantibiotics and other bioactive metabolites. The table lists these secondary metabolites according to the main producer types and other specific producer species. To date, more than 10,000 compounds are continuously isolated from different actinomycetales species where $34 \%$ are from Streptomyces and $11 \%$ are from rare actions. The major producers, the Streptomyces species, produce about $74 \%$ of all actinomycetales (around 7,600 compounds). The rest of the compounds (about $26 \%$ or 2500 compounds) [13].

Table 2. Estimated number of bioactive microbial metabolites according to their biological activities and producer strains (Adapting from Bérdy, [13])

\begin{tabular}{|c|c|c|c|c|c|}
\hline \multicolumn{6}{|c|}{ Bioactive secondary microbial metabolites } \\
\hline \multirow[t]{2}{*}{ Supply } & \multicolumn{2}{|c|}{ Antibiotics } & \multicolumn{2}{|c|}{ Bioactive compounds } & \multirow{2}{*}{$\begin{array}{l}\text { Total Bioactive } \\
\text { metabolites }\end{array}$} \\
\hline & Total & $\begin{array}{l}\text { (With other } \\
\text { activity) }\end{array}$ & $\begin{array}{l}\text { No antibiotic } \\
\text { activity }\end{array}$ & $\begin{array}{ll}\text { Antibiotics } & \text { plus } \\
\text { metabolites } & \\
\text { "Other bioactives } & \\
\end{array}$ & \\
\hline Bacteria & 2900 & (780) & 900 & $(1680)$ & 3800 \\
\hline Eubacteriales & 2170 & (570) & 580 & $(1150)$ & 2750 \\
\hline Bacillus sp. & 795 & (235) & 65 & (300) & 860 \\
\hline Pseudomonas sp. & 610 & (185) & 185 & (370) & 795 \\
\hline Myxobacter & 400 & (130) & 10 & (140) & 410 \\
\hline Cyanobacter & 300 & $(80)$ & 340 & (420) & 640 \\
\hline Actinomycetales & 8700 & (2400) & 1400 & (3800) & 10100 \\
\hline Streptomyces sp. & 6550 & (1920) & 1080 & (3000) & 7630 \\
\hline Rare actinos & 2250 & $(580)$ & 220 & $(800)$ & 2470 \\
\hline Fungi & 4900 & (2300) & 3700 & $(6000)$ & $(8600$ \\
\hline Microscopic fungi & 3770 & (2070) & 2680 & $(4750)$ & 6450 \\
\hline Penicillium/ & 1000 & $(450)$ & 950 & (1400) & 1950 \\
\hline Aspergillus & & & & & \\
\hline Basidiomycetes & 1050 & 200 & 950( & $(1150)$ & 2000 \\
\hline Yeasts & 105 & (35) & 35 & 70 & 140 \\
\hline Slime moulds & 30 & (5) & 20 & (25) & 60 \\
\hline
\end{tabular}

\subsection{Antibiotic Definition and History}

The Greek word for against (anti) and life (bios) makes up the word "antibiotic". Chinese has been acknowledged as one of the earliest civilization that used antibiotics, and the ancient Egyptian and Greeks were known to use molds and plants to cure infections. Nevertheless, this does not mean that antibiotic is a novel biological agent, it is simply a common microbial product which belongs to a larger group of anti-viral, anti-fungal and anti-parasitic drugs. When an antibiotic function to inhibit growth, it is called 'antibiosis'.

In general, antibiotics are complex chemical substances produced by microorganisms as secondary metabolites. These antibiotics react towards bacteria either by inhibiting their growth or killing them. This is a self-preservation technique used by many other microbes as well. Both synthetic and semisynthetic antibiotics can be defined this way as well, but this definition does not include plants and the compounds derived from them. This is because these materials are considered more as chemotherapeutic agents [14] and thus are termed as "antimicrobials". Nevertheless, they give the same bacteriostatic (inhibition of bacterial replication and growth)or bactericidal (death or lysis of bacterial cell) effects [15]. It should be noted that bacteriostatic compounds do not kill the bacterial cells, but it can give more time to the host to build up its immune system to fight against the infection. 
The production of specific toxic substances which are detrimental or inbitory towards other microorganisms has long been discovered by microbiologists in laboratory cultivations. However, this discovery was only widely acknowledged and appreciated in 1929 when Fleming noticed lysis of Staphylococcus aureus colonies which had been contaminated with a mold called Penicillium notatum. Fleming named the freely diffusible substance produced by the mold colony to surround itself as penicillin [16] and in the 1940s, this antibiotic was massively produced through Penicillium notatum caltivation. At that time, these antibiotics were mostly used to treat wounds infects during the World War II and this began the golden age of antibiotics research and development [16]. Today, antibiotics are popular in chemotherapy, plant pathology, food preservation, and veterinary medicine; they can also be found in biochemistry and molecular biology research tools.

\subsection{Synthesis of Antibiotics and Cell Growth Phase}

A single microbial type can produce various metabolites. For example, both Streptomyces griseus and Bacillus subtilis can produce more than 50 types of bioactive secondary microbial metabolites that may include antibiotics, ergot alkaloids, naphthalenes, nucleosides, peptides, phenazines, quinolones, terpenoids, and others. Antibiotics are produced by microbial fermentation on microbial genera inhabiting soil that is undergoing morphological differentiation [17]. For example, penicillin is produced only after the logarithmic growth phase of the cell (trophophase) is completed. The main production of the secondary metabolite occurs during the stationary phase of cell growth (idiophase) as shown in Figure 1.

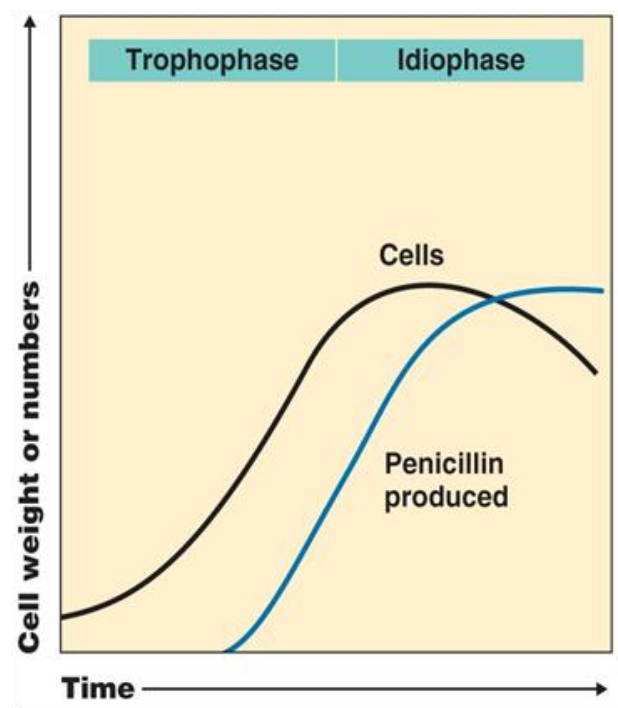

Figure 1 Profile of antibiotic cell growth phase showing that it starts to produce at $\log$ phase

\subsection{Antibiotics Producing Strains}

In order to improve and produce antibiotics in the large scale, in depth knowledge of the microbial producers' physiology, pathway regulations, and control methods are needed. Recently, research efforts have been devoted to elucidate at the molecular level and to understand more about the regulatory mechanisms involved in the control of the biosynthesis of antibiotics [18]. Most works have been focused in antibiotics produced by fungi and actinomycetes where a number of biochemical and genetic controls have been described to optimize the production levels of antibiotics in specific medium [19]. It is true that bacteria, fungi, algae, corals, sponges, plants and lower animals are among the common microorganisms that biosynthesize antibiotic compounds, but most secondary metabolites are actually biosynthesized by filamentous microorganisms like actinomycetes (about 75\%) and molds (17\%). When isolated from nature, about $40 \%$ of filamentous fungi and actinomyecetes can produce antibiotics (Figure 2). Moreover, about 180 different types of secondary metabolites can be produced by the Streptomyces species alone.

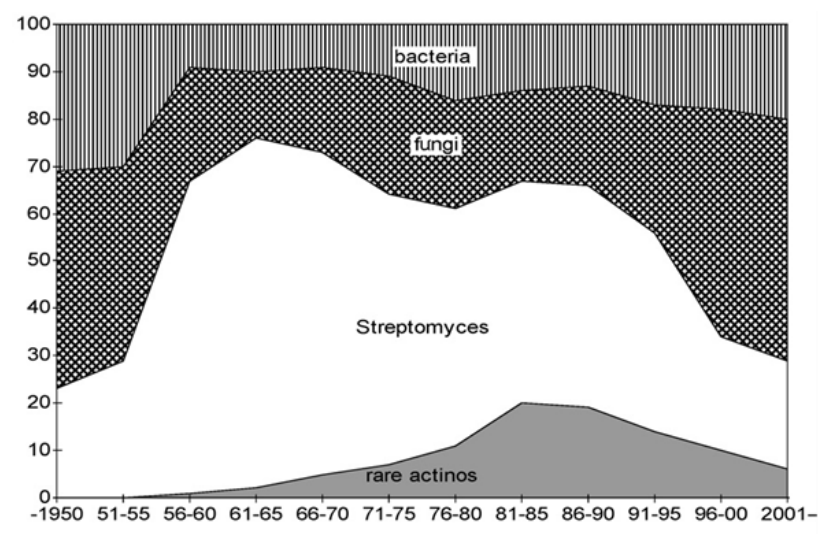

The distribution of the most active metabolites (antibiotics) based on their microbial source.

Figure 2 The distribution of the known antibiotics according to their microbial source (Adopting from Bérdy [13])

Streptomycetes are potent producers of secondary metabolites because around $45-55 \%$ of an estimated 10,000 archived antibiotic are produced by them $[4,20]$. They exhibit a wide range of biological activities; e.g. antibacterial (streptomycin, tetracycline, chloramphenicol), antifungal (nystatin), antiviral (tunicamycin), antiparasitic (avermeetin), immunosuppressive (rapamycin), antitumor (actinomycin, mitomycin $\mathrm{C}$, anthracyclines), enzyme inhibitive (clavulanic acid), and diabetogenic (bafilomycin, streptozotocin). Other than secondary metabolites, spore pigment actually have similar structures and they can be synthesized using the same mechanisms [21, 22].

Other than that, several antibiotics have also been isolated from different Bacillus strains, moenomycins, difficidins, bacillomycins and bacillaenes[23-25]. Mycobacteriumis another genus of bacteria with interesting antibiotic productivities. For instance, Reichenbach, et al. [26] found that approximately $80 \%$ of the isolated Mycobacterium produced compounds with antibiotic and antifungal activity. Some of the most important antibiotics with biological activities produced by microorganisms are listed in Table 3.

\subsection{Antibiotics and Gene Coding}

The biotechnology industry functions by harnessing the metabolic activities of various organisms to produce various compounds suitable for different industries. In this matter, two methods have been applied: optimization of fermentation process and improvement of strains [27]. Secondary metabolites are very sensitive towards changes in the environmental and cultural conditions. For instance, the in-vitro production of most antibiotics depends on the composition of the culture medium in 
which the producer organism is grown. For this reason, medium optimization has been the standard procedure for optimizing antibiotic production.

Moreover, the availability of nutrients affects the production of antibiotics as well. It has been proven through fermentation experiments that when there is a significant presence of unfavorable carbon sources or absence of phosphate, then the production of antibiotics can be increased $[29,30]$. Production of secondary metabolites is also influenced by the amount of nitrogen present in the culture [8]. The regulatory mechanisms of antibiotics production have not been fully understood, although it is postulated that it is related to the regulation of sporulation because both processes are driven by hormone-like regulatory factors, for example A-factor by $S$. griseus [31]. $12 \%$ of proteins coded by $S$. coelicolor has also been speculated as having regulatory functions, and in general, it can be said that the streptomycetes have complex regulatory apparatus.

Table 3. Antibiotic compounds, producer strains with the important biological activities

\begin{tabular}{|c|c|c|c|}
\hline & Compound & Producer & Biological activity \\
\hline 1. & AmphotericinB & Streptomyces nodosus & Antifungal \\
\hline 2. & Avermectin & S. avermitilis & Antiparasitic \\
\hline 3. & Anthracyclines & S. galileus & Antitumor \\
\hline 4. & Bafilomycin & $\begin{array}{l}\text { S. griseus } \\
\text { S. halstedii }\end{array}$ & $\begin{array}{l}\text { ATPase-inhibitor of MO, } \\
\text { Plant and animal cells }\end{array}$ \\
\hline 5. & Bialaphos & Streptomyces hygroscopicus & Herbicide \\
\hline 6. & DaunorubicinHCl & Streptomyces sp & Antitumoral \\
\hline 7. & Cephalosporin & Cephalosporiumchrysogenum & Antibiotic \\
\hline 8. & Chlortetracycline & Streptomyces aureofaciens & Antibiotic, growth promotant \\
\hline 9. & Chloramphenicol & S. venezuelae & $\begin{array}{l}\text { Antibacterial, } \\
\text { inhibitorof protein biosynthesis }\end{array}$ \\
\hline 10. & CyclosporinA & Trichodermapolysporum & Immunosuppressant \\
\hline 11. & DaunorubicinHCl. & Streptomyces sp & Antitumoral \\
\hline 12. & Doxorubicin $\mathrm{HCl}$ & Streptomyces peucetius & Antitumoral \\
\hline 13. & ErythromycinA & Streptomyces erythreus & Antibiotic \\
\hline 14. & Gentamicin & Micromonosporapurpurea & Antibiotic \\
\hline 15. & Hygromycin & S. hygroscopicus & $\begin{array}{l}\text { Antimicrobial, } \\
\text { immunosuppressive }\end{array}$ \\
\hline 16. & Kanamycin & Streptomyces canus & Antibiotic \\
\hline 17. & LincomycinHCl & Streptomyces lincolnensis & Antibiotic \\
\hline 18. & Mitosane & Streptomyces caespitosus & Antitumoral \\
\hline 19. & MitomycinC & S. lavendulae & $\begin{array}{l}\text { Antitumor, } \\
\text { Bindsto double-stranded DNA }\end{array}$ \\
\hline 20. & Oxytetracycline & Streptomyces rimosus & Antibiotic, feed additive \\
\hline 21. & Paclitaxel & Taxomycesandreanae & Antitumoral \\
\hline 22. & Penicillin & Penicilliumchrysogenum & Antibiotic \\
\hline 23. & Rifamycin & Amycolatopsismediterranei & Antibiotic \\
\hline 24. & Rapamycin & S. hygroscopicus & immunosuppressive, antifungal \\
\hline 25. & Salinomycin & Streptomyces albus & Growth promotant \\
\hline 26. & Spiramycin & Streptomyces ambofaciens & Antibiotic \\
\hline 27. & Streptomycin sulfate & Streptomyces griseus & Antibiotic \\
\hline 28. & Streptozotocin & S. achromogenes & Diabetogenic \\
\hline 29. & Teicoplanin & Actinoplanesteichomyceticus & Antibiotic \\
\hline 30. & Tetracycline $\mathrm{HCl}$ & Streptomyces aureofaciens & Antibiotic \\
\hline 31. & VancomycinHCl & Amycolatopsisorientalis & Antibiotic \\
\hline
\end{tabular}

\subsection{Antibiotics Types}

In this modern era, the antibiotics used in the medical field can be broadly divided into three types.

\subsubsection{Natural Antibiotics}

Natural antibiotics are also considered as homeopathic remedies that are produced by natural agents like fungi. These antibiotics are $100 \%$ natural with no artificial additives. Some examples of such homeopathic remedies include honey and Echinacea. The latter is identical to garlic and fungi which can find bacteria and viruses. It stimulates the production of cells in an immune system to attack infections by providing strength to blood pressure.

These antibiotics can be consumed on a daily basis without devastating side effects. For instance, an equal portion of honey and cinnamon can treat skin infections, insect bites and eczema. To treat viral, bacterial, parasites and fungi infections, the olive leaf is a good choice as well. Moreover, its extract can treat cold, herpes, flu, sinusitis, and allergies. Wild indigo has also been used to treat bronchitis, sore throat, mouth sores, tonsillitis, and swollen glands.

\subsubsection{Semi-synthetic Antibiotics}

Semi-synthetic antibiotics are chemically modified variants of natural antibiotics. Such antibiotics are altered for several reasons: to increase their efficacy, to lower or nullify the side effects, or to change the microbe range that is sensitive to them. An example of such antibiotics is ampicillin. The starting materials are compounds isolated from natural sources such as plants or bacterial or cell cultures which have large and complex molecules. Unlike synthetic antibiotics, semi-synthetic antibiotics are not built up using a stepwise combination of small and cheap (commonly petrochemicals) building blocks [33]. 
Semi-synthetic substitutions protect the ring by strict hindrance, which means it may actually inactivate certain penicillinases so that under some circumstances, resistant penicillins may potentiate penicillin G. However, the protective substitutions reduce the intrinsic activity of the synthetic penicillins themselves. Other properties which are affected too include absorption, protein-binding, excretion, and possible drug allergenicity. The effects on an antibacterial spectrum may be secondary to alteration of lipid solubility [34].

\subsubsection{Synthetic Antibiotics}

In the USA, bacterial infection is the main cause of health care expense. For some patient, the complications cannot be solved using simple antibiotic therapy and doctors have found limited antibiotic choices for patients in this health-risk category.

With advances in medical science, the development of synthetic antibiotics such as Linezolid and sulfonamides has provided new avenues in the treatment of drug resistant bacterial infections. These antibiotics are designed and produced in laboratories and they are often the only viable option to patients who are suffering from stubborn bacterial infections. In fact, synthetic penicillins are also prescribed to prevent widespread of resistant infections and public health crisis[35]. Synthetic antibiotics destroy the protein synthesis process before its initiation, which is a crucial replication element that controls bacteria survival.

\subsection{Antibiotic Classification}

Antibiotic classification can be done based on the bacterial spectrum (broad or narrow); administration route (injectable, oral or tropical); type of function (bactericidal or bacteriostatic); type of producer; biosynthesis pathway; and chemical structure. Most antibiotics are classified according to their chemical structures as this has been found as the most effective classification method. This has been illustrated in Table 4 where it is clear that different structural class have varying level of effectiveness, toxicity and allergic potential [36].

Table 4. Classification of antibiotics based on their structures

\begin{tabular}{|c|c|c|}
\hline Antibiotics & & Chemical structure \\
\hline 1. & Penicillins\&Cephalosporins & $\beta$-lactam ring \\
\hline 2. & $\begin{array}{l}\text { Aminoglycosides } \\
\quad(\text { e.g Streptomycin, neomycin, } \\
\text { amikacin) }\end{array}$ & $\begin{array}{l}\text { Amino sugars in a glycosidie } \\
\text { linkage }\end{array}$ \\
\hline 3. & $\begin{array}{l}\text { Macrolides } \\
\text { (e.g.erythromycinand } \\
\text { oleandomycin) }\end{array}$ & Macrooycliclocation \\
\hline 4. & Tetracyclines & Polycyclicnaphthone carboxide \\
\hline 5. & Chloramphenicol & $\begin{array}{l}\text { Nitrobenzene,Derivative of dichlor } \\
\text { acetic acid }\end{array}$ \\
\hline 6. & Peptide antibiotics & Peptide linked $\mathrm{D}$ and $\mathrm{L}$ amino acids \\
\hline 7.: & Antifungalantibiotics & Polyens \& nonpolyenes \\
\hline 8. & $\begin{array}{l}\text { Ansamacrolides } \\
\quad(\text { e.g.Streptovaricinsand } \\
\text { rifamycins })\end{array}$ & $\begin{array}{l}\text { Naphto and benzoquinone nuclei } \\
\text { derivatives }\end{array}$ \\
\hline 9. & $\begin{array}{l}\text { Anthracyclincantibiotics } \\
\text { (e.g.adriamycin\&duanomycin) }\end{array}$ & Anthracycline \\
\hline 10. & Unclassified & $\begin{array}{l}\text { Cycloserine, novobiocin } \\
\text { fusidic acid }\end{array}$ \\
\hline
\end{tabular}

\subsection{Antibiotics Spectra}

This classification separates the biological activity of antibiotics into broad, narrow, and limited spectra [36]. If the antibiotic has a wide range of Gram-positive and Gram-negative bacteria, then it is classified as having a broad spectrum. Otherwise, it will be classified as having a narrow spectrum. If the antibiotic only reacts against a certain type of organism or disease, then the antibiotic is said to have a limited spectrum.

\subsection{Modes of Action of Antibiotics}

As a low molecular weight organic natural product, the antibiotic can be active against other microorganisms at lower concentrations [4]. This activity develops through a limited number of mechanisms where the antibiotics interfere with cell wall peptidoglycan biosynthesis, cell membrane integrity,and protein synthesis and inhibit DNA replication and repair, transcription, and intermediate metabolism (Inhibitors of Protein Synthesis) (Figure 3a, b).

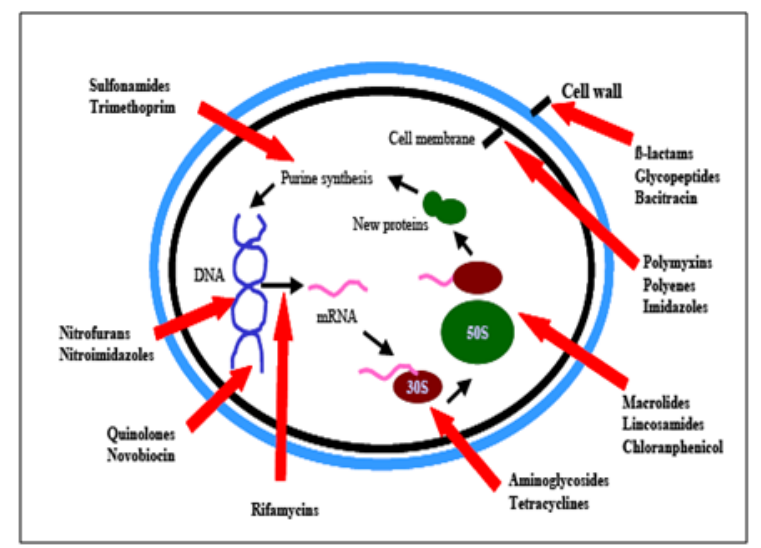

(a)

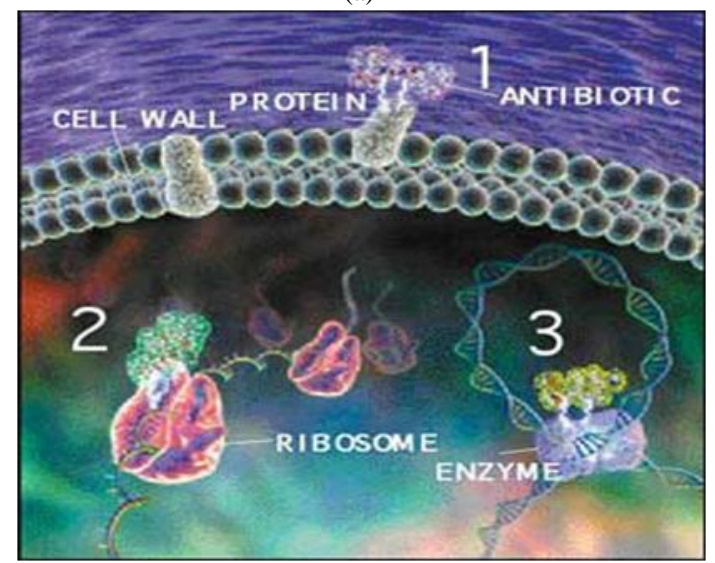

(b)

Figure 3. Site of action of most common antibiotics

In cell walls, the antibiotics block off the biosynthesis by inhibiting the enzymes responsible for the synthesis of different cell wall components, which is also the case for intermediate metabolism interference.Antibiotics can disorganize the structure or inhibit the function of bacterial membranes. In the synthesis of protein, antibiotics can impair the ribosomal subunits binding upon $50 \mathrm{~S}$ to prevent the translation and further binding upon $30 \mathrm{~S}$. This binding is unfavorable as it may lead to false translation that produces toxic and mutated proteins. For DNA replication, there are antibiotics that affect DNA 
replication and repair inhibit enzymes like gyrase, topoisomerase, and N-methyltransferase. Some antibiotics can also inhibit bacterial RNA polymerase subunits by resisting the entry of the first nucleotide essential for polymerase activation. Table 5 lists some of the more common classes of antimicrobials and their mechanisms of action.

Table 5 Classes of antibiotics, modes of action and possible side effects

\begin{tabular}{|c|c|c|c|c|}
\hline Scientific name & Trade names & Ordinary uses & Potential side effects & Mode of action \\
\hline \multicolumn{5}{|c|}{ Amino glycosides } \\
\hline Amikin & Amikin & \multirow{7}{*}{$\begin{array}{l}\text { Infections caused by Gram- } \\
\text { negative bacteria, such as E. coli } \\
\text { and Klebsiella particularly } \\
\text { P.aeruginosa. Effective against } \\
\text { aerobic bacteria and tularemia }\end{array}$} & \multirow{7}{*}{$\begin{array}{l}\text { Hearing loss, } \\
\text { Vertigo, } \\
\text { Kidney damage }\end{array}$} & \multirow{7}{*}{$\begin{array}{l}\text { Binding to the bacterial 30S subunit, } \\
\text { inhibiting the translocation of the peptidyl- } \\
\text { tRNA from the A-site to the P-site and also } \\
\text { causing misreading of mRNA, leaving the } \\
\text { bacterium unable to synthesize proteins } \\
\text { vital to its growth }\end{array}$} \\
\hline Gentamicin & Garamisin & & & \\
\hline Kanamycin & Kantrex & & & \\
\hline Neomycin & Mycifradin & & & \\
\hline Netilmicin & Netromyci-n & & & \\
\hline Tobramycin & Nebcin & & & \\
\hline Paromomycin & Humatin & & & \\
\hline \multicolumn{5}{|c|}{ Cephalosporins } \\
\hline Cefadroxil & Duricef & \multirow{4}{*}{$\begin{array}{l}\text { Good treatment against Gram } \\
\text { positive infections }\end{array}$} & \multirow{11}{*}{$\begin{array}{l}\text { Gastrointestinal upset and } \\
\text { diarrhea } \\
\text { Nausea, Allergic reactions }\end{array}$} & \multirow{11}{*}{$\begin{array}{l}\text { Similar mode of action as other beta-lactam } \\
\text { antibiotics: upset the synthesis of the } \\
\text { peptidoglycan layer of bacterial cell walls. }\end{array}$} \\
\hline Cefazolin & Ancef & & & \\
\hline Cefalotin & Keflin & & & \\
\hline Cefalexin & Keflex & & & \\
\hline Cefaclor & Ceclor & \multirow{5}{*}{$\begin{array}{l}\text { Less gram positive wrap, } \\
\text { improved gram negative cover } \\
\text { up. }\end{array}$} & & \\
\hline Cefamandole & Mandol & & & \\
\hline Cefoxitin & Mefoxin & & & \\
\hline Cefprozil & Cefzil & & & \\
\hline Cefuroxime & $\begin{array}{l}\text { Ceftin, } \\
\text { ZinnatCep } \\
\end{array}$ & & & \\
\hline Cefoperazone & Cefobid & \multirow{2}{*}{$\begin{array}{l}\text { Improved coverage of Gram } \\
\text { negative organisms, except } \\
\text { Pseudomonas. Reduced Gram } \\
\text { positive cover up. }\end{array}$} & & \\
\hline Cefotaxime & Claforan & & & \\
\hline \multicolumn{5}{|c|}{ Macrolides } \\
\hline Azithromycin & $\begin{array}{l}\text { Zithromax, } \\
\text { Sumamed, Zitrocin }\end{array}$ & & & \multirow{4}{*}{$\begin{array}{l}\text { Inhibition of bacterial protein biosynthesis } \\
\text { by binding reversibly to the subunit } 50 \mathrm{~S} \text { of } \\
\text { the bacterial ribosome, thereby inhibiting } \\
\text { translocation of peptidyl tRNA. }\end{array}$} \\
\hline Clarithromycin & Biaxin & & & \\
\hline Dirithromycin & Dynabac & & & \\
\hline Erythromycin & $\begin{array}{l}\text { Erythocin, } \\
\text { Erythroped }\end{array}$ & & & \\
\hline Scientific name & Trade names & Common uses & Possible side effects & Mode of action \\
\hline \multicolumn{5}{|c|}{ Nitrofurans } \\
\hline Furazolidone & Furoxone & \multirow[t]{2}{*}{$\begin{array}{l}\text { Bacterial or protozoal diarrhea } \\
\text { or enteritis Nitrofurantoin } \\
\text { Urinary tract infections }\end{array}$} & & \\
\hline Nitrofurantoin & Furoxone & & & \\
\hline \multicolumn{5}{|c|}{ Penicillins } \\
\hline Amoxicillin & Novamox, Amoxil & \multirow{5}{*}{ 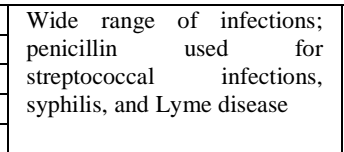 } & \multirow{5}{*}{$\begin{array}{l}\text { Gastrointestinal upset and } \\
\text { diarrhea } \\
\text { Allergy with serious } \\
\text { anaphylactic reactions, Brain } \\
\text { and kidney injure (rare) }\end{array}$} & \multirow{5}{*}{$\begin{array}{l}\text { Identical mode of action as other beta- } \\
\text { lactam antibiotics: interrupt the synthesis of } \\
\text { the peptidoglycan layer of bacterial cell } \\
\text { walls }\end{array}$} \\
\hline Ampicillin & Principen & & & \\
\hline Dicloxacillin & Dynapen & & & \\
\hline Penicillin G & Pentids & & & \\
\hline Ticarcillin & Ticar & & & \\
\hline \multicolumn{5}{|c|}{ Penicillin combinations } \\
\hline Amoxicillin/ clavulanate & Augmentin & & & \multirow{4}{*}{$\begin{array}{l}\text { The second compound inhibits the beta- } \\
\text { lactamse produced by the pathogens. }\end{array}$} \\
\hline Ampicillin/ sulbactam & Unasyn & & & \\
\hline Piperacillin/ tazobactam & Zosyn & & & \\
\hline Ticarcillin/ clavulanate & Timentin & & & \\
\hline \multicolumn{5}{|c|}{ Quinolones } \\
\hline Ciprofloxacin & Ciproxin, Ciprobay & & Nausea (rare), irreversible & Inhibit the bacterial DNA gyrase, thereby \\
\hline Nalidixic acid & Gram Negative. & bacterial & break to central nervous & inhibiting DNA duplication and \\
\hline Norfloxacin & Noroxin & community-acquired & system (uncommon), & transcription \\
\hline Ofloxacin & Floxin, Ocuflox & $\begin{array}{l}\text { pneumonia, bacterial diarrhea, } \\
\text { mycoplasmal infections, } \\
\text { gonorrhea. }\end{array}$ & tendinosis (rare) & \\
\hline Scientific name & Trade names & Ordinary uses & Potential side effects & Mode of action \\
\hline & & Sulfonamide & & \\
\hline Sulfacetamide & Sulamyd, Bleph-10 & Urinary tract infections (except & Nausea, vomiting, and & Folate synthesis inhibition. They are \\
\hline Sulfadiazine & Micro-Sulfon & sulfacetamide, used for eye & diarrhea & competitive inhibitors of the enzyme \\
\hline Sulfamethizole & Thiosulfil Forte & infections. & $\begin{array}{l}\text { Allergy (including skin } \\
\text { rashes) } \\
\text { Crystals in urine } \\
\text { Kidney failure } \\
\text { Decrease in white blood cell } \\
\text { count } \\
\text { Sensitivity to sunlight. }\end{array}$ & $\begin{array}{l}\text { dihydropteroate synthetase. Folate is } \\
\text { necessary for the cell to synthesize nucleic } \\
\text { acids and in its absence cells will be } \\
\text { incapable to divide. }\end{array}$ \\
\hline
\end{tabular}




\begin{tabular}{|c|c|c|c|c|}
\hline \multicolumn{5}{|c|}{ Tetracyclines } \\
\hline Doxycycline & Vibramycin & \multirow{3}{*}{$\begin{array}{l}\text { Chlamydial infections, Lyme } \\
\text { disease, acne rickettsial } \\
\text { infections, malaria. Malaria is } \\
\text { caused by a protest and not a } \\
\text { bacterium. }\end{array}$} & \multirow{3}{*}{$\begin{array}{l}\text { Gastrointestinal } \\
\text { Sensitivity to supset, } \\
\text { Possible toxicity to the } \\
\text { mother and fetus during } \\
\text { pregnancy. }\end{array}$} & \multirow{3}{*}{$\begin{array}{l}\text { Inhibiting the binding of aminoacyl-tRNA } \\
\text { to the mRNA-ribosome complex. }\end{array}$} \\
\hline Oxytetracycline & Terramycin & & & \\
\hline Tetracycline & $\begin{array}{l}\text { Sumycin, } \\
\text { Achromycin V, } \\
\text { Steclin }\end{array}$ & & & \\
\hline \multicolumn{5}{|c|}{$\begin{array}{ll} & \text { Others } \\
\end{array}$} \\
\hline Chloramphenico-1 & Chloromyce-tin & $\begin{array}{l}\text { Topical use, Historic: typhus, } \\
\text { cholera. gram negative, gram } \\
\text { positive, anaerobes }\end{array}$ & Rarely: a plastic anemia. & $\begin{array}{l}\text { Inhibits bacterial protein synthesis by } \\
\text { binding to the 50S subunit of the ribosome }\end{array}$ \\
\hline Fusidic acid & Fucidin & & & \\
\hline Metronidazole & Flagyl & $\begin{array}{l}\text { Infections caused by anaerobic } \\
\text { bacteria; also amoebiasis, } \\
\text { trichomoniasis, Giardiasis }\end{array}$ & & \\
\hline Thiamphenicol & & $\begin{array}{l}\text { Gram-negative, Gram-positive, } \\
\text { anaerobes. } \\
\text { Widely used in veterinary } \\
\text { medicine. }\end{array}$ & $\begin{array}{l}\text { Lacks known anemic } \\
\text { Side effects. }\end{array}$ & $\begin{array}{l}\text { A chloramphenicol analog. May slow } \\
\text { down bacterial protein synthesis by } \\
\text { binding to the } 50 \mathrm{~S} \text { subunit of the ribosome }\end{array}$ \\
\hline
\end{tabular}

\subsection{Synergism and Antagonism between Antibiotics}

Drugs that greatly enhance the antibacterial activity of another are known by three mechanisms atleast.The first is the blocking of successive stepsin a metabolic sequence essential for microbial growth, this can be seen in the mixture of sulfonamide that inhibits para-aminobenzoic acid (PABA) uptake and trimethoprim which in turn inhibits dihydrofolate reductase. The second mechanism involves the inhibition of an enzyme (betalactamase from Gram-negative bacteria) that can destroy a drug (such as ampicillin) by using another drug (like methicillin).The third mechanism is the most extensively studied and is based on the ability of cell-wall inhibitors to enhance the passage of otherdrugs into thecytoplasm of the bacterial cell andpermit them to reach lethal concentrations onribosomes.

Antagonism refers to a decrease in bacteriostatic or bactericidal action in the curative effect in vivo [37].

\subsection{Antibiotic Susceptibility Testing}

To measure the in vitro activity of antibiotics, two basic quantities must be taken into account, namely the minimum inhibitory concentration (MIC) and the minimum bactericidal concentration (MBC). MIC refers to the lowest amount of antibiotic needed to initiate growth inhibition of colonies on a place or to reduce turbidity in the broth culture under standard conditions. Its calculation is as shown in Figure 1. Meanwhile, MBC refers to the lowest amount of antibiotic needed to kill $99.9 \%$ of the original inoculum within a specific time frame. If the antibiotic is effective, it means that either the MIC or MBC has been achieved at the targeted infected area. Nevertheless, its dosage, route and frequency of effective administration are also affected by the antibiotic's pharmacological absorption and distribution [38]. The most popular method to test the susceptibility of antibiotics in clinical laboratories is the disk diffusion test (Figure 4). This test inoculates the bacterial isolate uniformly onto an agar plate's surface. Then, the plate's surface is applied with a filter disk which has been impregnated with a standard dosage of antibiotic. The antibiotic will diffuse into the adjacent medium and a gradient of antibiotic will then surround the disk. After incubation, a bacterial lawn will appear on the plate where the inhibition zone will be around the antibiotic disk. Its size depends on the antibiotic's diffusion rate, the microorganism's sensitivity degree and the bacterium's growth rate. This inhibition zone is inversely related to MIC [38].

The conditions to carry out this test have been standardized and thus all antibiotics have their standard inhibition zone.These standard inhibition zones are as shown in Figure 5 for several types of antibiotics. If it happens that the tested antibiotic shows an inhibition zone which is larger than the standard zone, then the organism is said to be sensitive to the antibiotic and vice versa.

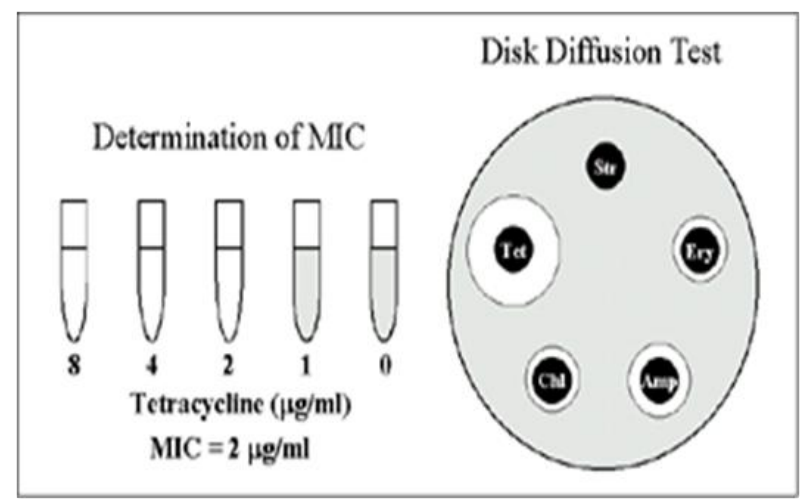

Figure 4 Determination of minimum inhibitory concentration (MIC) for antibiotic

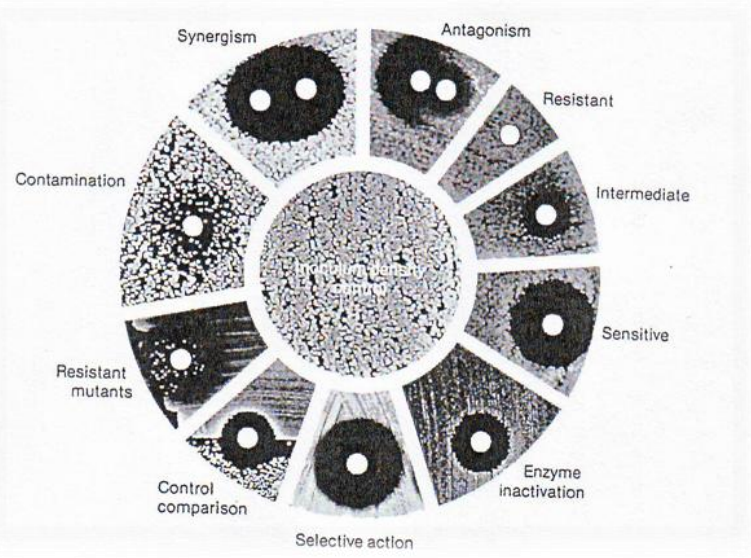

Figure 5 Antibiotic sensitivity testing using disc diffusion test showing the different types of zone which noticed around the zone (Adapted from Singleton, [47])

\subsection{Antibiotic Resistance}

A number of international organizations such as the World Organization for Animal Health (OIE), the Food and Agriculture Organization (FAO) and the World Health Organization (WHO) have jointly agreed that the increasing amount of antimicrobial-resistant pathogenic bacteria has posed 
a threat to both human and animal health. This is because these germs have become immune to some common types of antibiotics and thus cannot be eliminated easily. Thus, it will aggravate diseases that are hard to treat as the bacterial infection will continue rather than respond to the antibiotics prescribed.

Chait, et al. [39] reported that antibiotics promote the spread of clinical resistance because of frequent usage. This eliminates the usefulness of antibiotics, causing some clinical infections dangerously untreatable.Torella et al. [40] mentioned a few pathogens that have grown immune to antibiotics such as tuberculosis and MRSA. Thus, clinical treatment has since twisted more progressively towards multi-antibiotic therapies to synergistically kill the infection.

Before penicillin was commercially produced to cure bacterial infections, antibiotics discovered in Germany in the 1800 s were toxic to mammals and were very unstable. Even after penicillin was discovered, Fleming had also warned that some bacteria would mutate and become resistant to penicillin [41]. Although the medical field has advanced in various ways from the time of Fleming, bacteria mutation continues to threaten the human population. The network of resistance is presented in Figure 6.

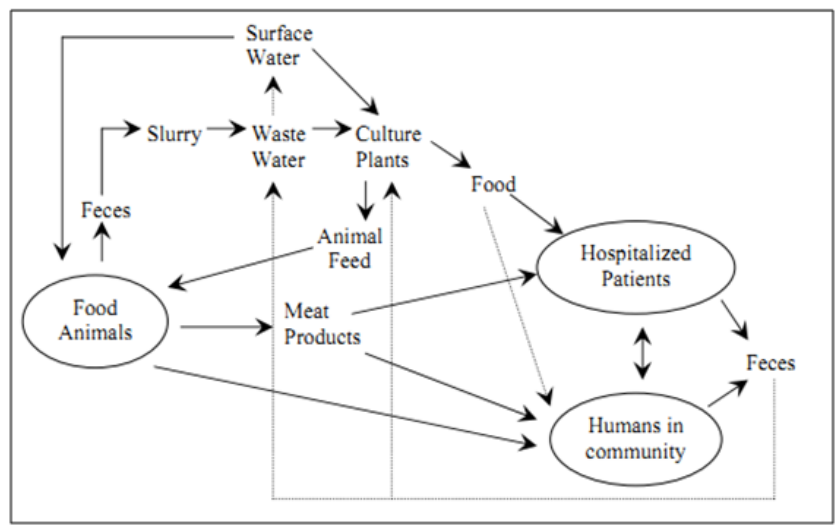

Figure 6 Network of Resistance. Main reservoirs of bacteria resistance to antibiotics include circular items. Antibiotics as a selective pressure on the main reservoirs. All shares refer to the ways of transmission (Adapted from Witte, [63])

The growing resistance of bacteria towards antibiotics is actually a natural evolutionary response induced by continuous exposure to these drugs. This is specifically termed as the intrinsic or acquired ability of the bacteria to withstand the inhibitory concentration of an antibiotic. Intrinsic ability is gained through failure of the prescribed antibiotic to reach its target, a lack of affinity for the target, the presence of efflux pumps, or the possession of other chromosomal resistance mechanisms [42]. From clinical aspect, acquired resistance is much more important and significant because of the possible spread of resistant genes through a sensitive microbial population. A number of gene transfer systems can be used to collect these genes, for example the bacterial conjugative plasmids, the transposable elements and the integrin systems. The integrin systems can mobilize the genes causing antibiotic resistance from a DNA system to another and from resistive bacterial cell to susceptible ones [43].

Some antibiotics tend to weaken the immune system[44]. For example, Stetsenko, et al.[45] discovered that titracyclines cause hemolytic anemia and leucopenia and the effect intensified if the antibiotic was used for a prolonged period of time and in high doses. Streptomycin and chloroamphenicol reduce neutrophil production, causing neutropenia. In fact, around 30 scientists from academia and industry had jointly presented a priority list of steps essential to be taken to tackle this global crisis in the Banbury Conference Center in New York [46].

Resistance of antibiotics may involve one or more of the following mechanisms: mutation such as in Mycobacterium tuberculosis; inactivation or degradation of antibiotics by some enzymes like $\beta$-lactamases; occurrence of efflux mechanisms, for example the inducible cytoplasmic membrane protein mediates the efflux of tetracycilines in some Gram-negative bacteria; diminished permeability that causes an increase in MIC, for instance by Enterobacter aerogenes with certain antibiotics; increased synthesis of target metabolite crush due to increasing PABA as a form of resistance of sulfonamides; acquisition of an exogenous determinateof resistance like the in vivo transfer of vacomycin immuned towards Enterococcus fecalis to multidrug-resistant strain of Stapheyloccus aureus; and inducible resistance to antibiotics like $\beta$-lactam antibiotics [47]. The use of genotypic approaches for antimicrobial resistance genes detection has also been promoted as a way to increase the rapidity and accuracy of susceptibility testing.

\subsection{How to Take Antibiotics?}

Normal antibiotics prescription period can be three days or seven to ten days. Doctor prescribed antibiotics need to be taken at regular, specified time intervals, such as every four, six, eight or 12 hours and sometimes there may be other specific instructions Some antibiotics can be taken on an empty stomach, but others must be taken an hour before, during or two hours after meal. There are antibiotics that cannot be taken with certain foods and drinks and alcohol is prohibited if metronidazoleis to be consumed. Tetracycline cannot be taken with dairy products, including milk, as they will reduce the antibiotics absorption into bloodstream. Bacterial resistance to antibiotics often occurs when the prescribed amount is not finished or not consumed as directed by a doctor. Antibiotics are usually prescribed in tablets, capsules or syrup for children. They can also be given by injection or applied directly to infected part as drops, lotions or ointments.

\subsection{Antibiotic Side Effects}

The severity of antibiotic side effects can be different from simple to life-threatening reactions like labored breathing and asthmatic attack. Feeling sick, diarrhea and being sick are the most common antibiotics side effects. There can also be digestive tract and infections of the mouth due to the destruction of the good bacteria. More serious antibiotic side effects include kidney stone formation with sulfonamides; increased sun exposure sensitivity with tetracyclines; blood clotting with cephalosporins; deafness with erythromycin; blood disorders with trimethoprim; and etc. Penicillin, erythromycin and cephalosporinscan cause colitisin older people and lead to severe diarrhea as well. Side effects often occur due to allergy to antibiotics, especially penicillin which can cause swelling of the tongue and face, rashes and difficulty in breathing. About 90,000 people die because of super bugs like Staphylococcus aureus, which is the deadly resistivity. Table 5 illustrates the side effect of some antibiotics.

\subsection{Antibiotic Uses}

Antibiotics are used in veterinary medicine, poultry, cattle, fishes and in human medicine. Antibiotics are needed in large 
quantities in animal farming to prevent and treat infections, but smaller quantities are also used to promote growth. Bacterial infections in fruits and vegetables can be treated by antibiotics like streptomycin and oxytetracycline. However, the downside of such massive applications is that these antibiotics, often found in liquid waste at animal feedlots, have contaminated surface and ground water. These residues have also been found in sewerage treatment plants and important water resources across the European continent. Consequently, many microorganisms which are essential to keep the environment's balance have been killed unintentionally and the amount of resistant strains has multiplied as they have found favorable conditions to survive.

\subsection{Four Types of Antibiotic Reaction}

Drug-induced hypersensitivity reactions are normally caused by antibiotics such as penicillin and the sulfonamides. This type of reactions has four kinds of immunologic mechanism: Type I immediate hypersensitivity reactions; Type II-cytotoxic reactions; Type III-delayed, immune complex allergic reactions; and Type IV-cell-mediated hypersensitivity reactions. Systemically, they are expected to have an entire-body effect via the bloodstream through four stages-absorption, distribution in the body, metabolized, and disposal. These stages may be chronologically or concurrent.

\subsection{Antibiotics Metabolism}

\subsubsection{Absorption}

Absorption is the flow of drug in blood streams and is heavily dependent on the amount and type of antibiotic prescribed as well as the mode of administration. The antibiotic can be administered orally where the antibiotic will be digested after being disintegrated, crumbled, and dissolved in the stomach. Some active ingredients will then pass through the stomach wall to flow into the bloodstream while some will flow into the intestine before being absorbed into the bloodstream. The undistributed ingredients will flow into the liver to be partially transformed or eliminated. This is also termed as the "first-pass metabolism".

Alternatively, the antibiotic can be administrated in parenteral ways such as through injection (intravenous, intramuscular or subcutaneous), transcutaneous route (patches or ointments), granules (to melt under the tongue), rectal (suppositories), and etc. This means that the antibiotic is introduced and distributed without undergoing extensive firstpass metabolism.

\subsubsection{Distribution}

The antibiotic will be distributed throughout the body through the bloodstreams. It then exerts its action after reaching the target, which may be a certain type of cell, site of infection, and etc.

\subsubsection{Metabolism}

This entails the purification of the entire body by degrading the antibiotic in phases for easier elimination. Some active ingredients are naturally discarded through the liver, kidneys, or lungs. This is a self-therapeutic activity and the products are called metabolites.

\subsubsection{Elimination}

The active ingredients and/or metabolites can also be eliminated through the urinary bladder, in feces, or sometimes through the lungs. The lungs can help to eliminate substances that can evaporate easily.

\subsection{Antibiotic Assay Methods}

Practical assaying fermentation samples are very important to study the antibiotic production of actinomycetes. The dilution test mentioned earlier is one of the most widely used methods [48]. Some other methods include the agar diffusion test or cup test [49] and the linear diffusion test [50]. The cup test is popular for studying the bioassay of penicillin-containing solutions [51] when the antibacterial agent is also an aggressive bacteriostatic acidic substance with relatively low molecular weight compared to most actinomycete antibiotics which have higher molecular weight and are mostly neutral or basic. However, the diffusion rate depends on the $\mathrm{pH}$ and agar medium's composition [52] and thus it is difficult to interpret the agar diffusion assays in solutions with a mixture of antibiotic substances [53]. For better interpretation, it is better to use the dilution method.

In microbiological assays, the type of test organism has to be chosen carefully because some bacteria are relatively more sensitive towards certain antibiotics than others. The success of finding antibiotic-resistant or antibiotic-dependent test organisms have been previously reported [48], but the results are not completely satisfactory as the resistance and dependency have not been specified [54].

As more knowledge is gained regarding the chemistry of actinomycete, some complete or partial chemical procedures have been introduced to analyze fermentation samples. For example, the fermentation samples of streptomycin have been studied using the formation of maltol from streptomycin through alkaline degradation [55] and the formation of hydroxymethylfurfural in mannosidostreptomycin through acidic degradation [56]. Even though these methods are considerably more efficient, analyses of pure antibiotic materials' aqueous solutions with complex organic substance are always complicated and uncertain. Thus, it seems that microbiological methods will be used more widely than chemical assay methods although the latter are more specific, since the former are more sensitive and can be comparatively accurate under controlled conditions [50].

The diffusion assay of antibiotics employing a disc plate method has the great virtue of convenience, simplicity, sensitivity, efficiency, and dependability [57, 58]. A chemical or physicochemical test, if validated as completely specific for the active component, may be more accurate than results generally achieved with microbiological procedures [59].

A chemical or physical test has been often more amenable to automation than microbiological procedures [60]. Recently, automation has made more efficient and accurate use of turbidimetric and colorimetric assays [61]. Nevertheless, microbiological tests have broader application and are easier to establish because they provide a valid measure of antibiotic activity with little danger, generally, of interference from biologically inactive components or degradation products. Particularly, the disc plate method persists in wide use [58]. 


\subsection{Antibiotic Sensitivity Tests}

Antibiotic sensitivity tests are performed to determine the susceptibility of pathogens to certain types of antibiotics. The result of these tests is called an antibigram which enables the clinician to choose the optimal active antibiotic for chemotherapy and to discard antibiotic which is resistant to pathogens. The sensitivity of pathogens can be determined using the disc diffusion test, dilution test (to determine MIC), E-test, and the break point test. The disc diffusion test is preferred for bacteria that can produce obvious growth after an overnight incubation. Meanwhile, the dilution test is mostly conducted to determine an organism's ability to grow under a certain concentration of antibiotics in a liquid or solid medium. The Etest is read by noting the lowest concentration of antibiotic which prevents the growth. The break point test uses dilution test to determine which strain is resistant or sensitive[47].

\subsection{SUMMARY}

Antibiotics are produced by microorganisms and service functions for the survival of the organisms that produce them. To date, a wide range of identified antibiotics are produced by the members of the Streptomyces genus, but it is estimated that only $3 \%$ has been discovered so far. Antibiotic is a combating weapon that is used to fight against other members in the community as well as an agent of symbiosis between microbes and plants, nematodes, insects, and higher animals. Nevertheless, it has also found applications in chemotherapy, plant pathology, food preservation, veterinary, and biochemistry and molecular biology research field. Classifying the antibiotics according to their chemical structures is the most acceptable classification method although there are other methods. Also, based on antibiotic type, different antibiotic has a different mode of action for killing the pathogens. Antibiotic resistance can be treated with multi-drug synergistic effect, which in turn can be determined by several methods in the biological fluid.

\section{References}

[1] Navon-Venezia, S., R. Feder, L. Gaidukov, Y. Carmeli, and A. Mor 2002. Antibacterial Properties of Dermaseptins4 Derivatives with in Vivo Activity. Antimicrob Agents Chemother. 46(3): 689-94.

[2] Cragg, G. M., D. J. Newman, and K. M. Snader. 1997. Natural Products in Drug Discovery and Development. Journal of Natural Products. 60(1): 52-60.

[3] Scholar, E. M. and W. B. Pratt. 2000. The Antimicrobial Drugs. 2nd Edition. Oxford University Press, Oxford, UK.

[4] Demain, A.L. 1999. Pharmaceutically Active Secondary Metabolites of Microorganisms. Applied Microbiology and Biotechnology.52(4): 45563.

[5] Demain, A.L. and A.Fang, 2000. The Natural Functions of Secondary Metabolites. Advances in Biochemical Engineering/Biotechnology. 69(1): 1-39.

[6] Kieslich, K. 1986. Production of Drugs by Microbial Biosynthesis and Biotransformation. Possibilities, Limits and Future Developments. $1^{\text {st }}$ Communication. Arzneimittelforschung. 36(4): 774-8.

[7] Wells, J. S., J. C. Hunter, G. L. Astle, J. C. Sherwood, C. M. Ricca,W. H. Trejo, D. P. Bonner, and R. B. Sykes. 1982. Distribution of BetaLactam and Beta-lactone Producing Bacteria in Nature. Journal Antibiotic (Tokyo). 35(7): 814-21.

[8] Aharonowitz, Y. 1980. Nitrogen Metabolite Regulation of Antibiotic Biosynthesis. Annual Review of Microbiology. 34(1): 209-33.

[9] Goodman, R.N. 1959. The Influence of Antibiotics on Plants and Plant Disease Control. In: Antibiotics: Their Chemistry and Non-medical Uses. H.S. Goldberg, Ed. D. Vannostr And And Company, Inc. Princeton, NJ. 322-448.

[10] O. muraS. 1992. Trends in the Search for Bioactive Microbial Metabolites. Journal of Industrial Microbiology.10(3-4): 135-156.
[11] Zedan, H. 1993. The Economic Value of Microbial Diversity. BioTechnology. 43: 178-185.

[12] Miyadoh, S. 1993. Research on Antibiotic Screening in Japan Over the Last Decade: A Producing Microorganisms Approach. Actinomycetologica. 9: 100-106.

[13] Bérdy, J. 2005. Bioactive Microbial Metabolites, A Personal View. Journal of Antibiotics. 58(1): 1-26.

[14] Jurgens, M. H. 1997. Animal Feeding and Nutrition. Eighth Edition. Kendall/Hunt Publishing, Company, Dubuque, IA.

[15] Scholar, E. M. and W. B. Pratt. 2000. The Antimicrobial Drugs. 2nd edition. Oxford University Press, Oxford, UK.

[16] Garrod, L. P. and F. O'Grady. 1971. Antibiotics and Chemotherapy. 3d ed.).

[17] Vining, L.C. 1990. Functions of Secondary Metabolites. Annual Review of Microbiology. 44: 395-427.

[18] Roessner, C.A. and A.I. Scott. 1996. Genetically Engineered Synthesis of Natural Products: From Alkaloids to Corrins. Annual Review of Microbiology. 50(1): 467-90.

[19] DeLorenzo, V. 1985. Factors Affecting Microcine492 Production. Journal of Antibiotic (Tokyo). 38(3): 340-45.

[20] Lazzarini A, L.Cavaletti,G. Toppo and F. Marinelli. 2000. Rare Genera of Actinomycetes as Potential Producers of New Antibiotics. Antonie Van Leeuwenhoek. 78(3-4): 399-405.

[21] Metsä-Ketelä M, V.Salo, L.Halo, A.Hautala, J.Hakala, P.Mäntsälä andK.Ylihonko. 1999. An Efficient Approach for Screening Minimal PKS Genes from Streptomyces. FEMS Microbiology Letters. 180(1): $1-6$.

[22] Nakano, T., K. Miyake, M. Ikeda, T. Mizukami, R. Katsumata. 2000. Mechanism of the Incidental Production of a Melanin-like Pigment During 6-Demethylchlortetracycline Production in Streptomyces Aureofaciens. Applied and Environmental Microbiology. 66(4): 14001404.

[23] Parekh, S., V. A.Vinci, and R. J. Strobel. 2000. Improvement of Microbial Strains and Fermentation Processes. Applied Microbiology and Biotechnology. 54(3): 287-301.

[24] Zweerink, M.M. and A. Edison. 1987. Difficidin and Oxydifficidin: Novel Broad Spectrum Antibacterial Antibiotics Produced by Bacillus Subtilis. III. Mode of Action of Difficidin. Journal of Antibiot (Tokyo). 40(12): 1692-97

[25] Pinchuk, I. V., P. Bressollier, B. Verneuil, B. Fenet, I. B. Sorokulova, F. Megraudand, M. C.Urdaci. 2001. In Vitro Anti-helicobacter Pylori Activity of the Probiotic Strain Bacillus Subtilis3 is due to Secretion of Antibiotics. Antimicrob Agents Chemother. 45(11): 3156-61.

[26] Reichenbach, H., K. Gerth, H. Irschik, B. Kunzeand G. Hofle. 1988. Myxobacteria: A Source of New Antibiotics. Trends Biotechnology. 6: $115-121$.

[27] Parekh, S., V. A Vinci and R. J. Strobel. 2000. Improvement of Microbial Strains and Fermentation Processes. Applied Microbiology and Biotechnology.54(3): 287-301.

[28] Bunch, A. W. and R. E. Harris 1986. The Manipulation of MicroOrganisms for the Production of Secondary Metabolites. Biotechnology \& Genetic Engineering Reviews.4: 117-144.

[29] Aharonowitz, Y, A.L. Demain. 1978. Carbon Catabolite Regulation of Cephalosporin Production in Streptomyces clavuligerus. Antimicrobial Agents and Chemotherapy. 14 (2): 159-164.

[30] McDowall, K. J., A. Thamchaipenet and I. S. Hunter. 1999. Phosphate Control of Oxytetracycline Production by Streptomyces Rimosus is at the Level of Transcription from Promoters Overlapped by Tandem Repeats Similar to Those of the DNA-Binding Sites of the Ompr Family. Journal of Bacteriology. 181(10): 3025-3032.

[31] Horinouchi, S. and T. Beppu. 1992. Regulation of Secondary Metabolism and Cell Differentiation in Streptomyces: A-Factor as a Microbial Hormone and the Afsrprotein as a Component of a TwoComponent Regulatory System. Gene. 115 (1-2): 167-172.

[32] Bentley S. D, K. F. Chater, A. -M.Cerdeño-Tárraga, G. L. Challis, N. R. Thomson, K. D. James and et al. 2002. Complete Genome Sequence of the Model Actinomycete Streptomyces coelicolor A3(2). Nature. 417(6885): 141-147.

[33] Boehm, M., C.Peter, Fuenfschilling, M. Krieger, E. Kuestersand F.Struber. 2007. An Improved Manufacturing Process for the Antimalaria Drug Coartem. Part I Org. Process Research \& Development. 11(3): 336-340.

[34] Stephanie, P. 2007. The pharaohs' Pharmacists. New Scientist. 15 December 2007. 40-43.

[35] Kalant, H. 1965. The Pharmacology of Semisynthetic Antibiotics. The Canadian Medical Association Journal. 93(16): 839-843.

[36] Vandamme, E.J.1984. Antibiotic Search and Production: An Overview. In: Vandamme EJ (Ed) Biotechnology Of Industrial Antibiotics. New York: Marcel Dekker. 3-32. 
[37] Jawetz, E. 1975 Synergism and Antagonism among Antimicrobial drugs-A(1975).Western Journal of Medicine. 123: 87-91.

[38] Patrick, R., M, Rosenthal S. K. and A. P. Michael. Medical Microbiology. 6th Edition 2009. ISBN: 978-0-323-05470-6 960.

[39] Chait, R., K. Vetsigian and R.Kishony. 2012. What counters antibiotic resistance in nature? Naturechemical Biology. Vol. 8.25.www.nature.com/naturechemicalbiology.

[40] Torella, J. P., R. Chait and R. Kishony. 2010. Optimal Drug Synergy in Antimicrobial Treatments. Pols Computational Biology.6(6): 1-9.

[41] Levy, S. B. 1992. The Antibiotic Paradox: How Miracle Drugs Are Destroying the Miracle. Plenum Press, New York, NY.

[42] Woodford, N. and M.J. Ellington, 2007. The Emergence of Antibiotic Resistance by Mutation. Clinical Microbiology and Infection. 13(1): 518 .

[43] Bennett, P.M. 2008. Plasmid Encoded Antibiotic Resistance: Acquisition and Transfer of Antibiotic Resistance Genes in Bacteria. British Journal of Pharmacology. 153(3): 347-357.

[44] Zagury, F.T.R. 2006. The role of antibiotics in immunosuppressive Diseases. Advances in Pork Production. 17: 161-163.

[45] Stetsenko, O. N., I. A. Poberri, M. I. Ul'inaov, D. P. Lindner. 1981. Effect of Tetracycline on the Immune and Hematopoietic System on Infant Rabbits. Anibiotiki. 26: 11: 856-860.

[46] Bush,K., P. Courvalin, D. Dantasand et al. 2011. Tackling Antibiotic Resistance. Nature Reviews/ Microbiology.9: 894-896.

[47] Singleton P.2004. Bacteria in Biology, Biotechnology and Medicine $6^{\text {th }}$ Edition. Man Against Bacteria Chapt. 15: 450-457.

[48] Waksman, S. A. and H. C. Rerlly.1945. Agar-streak Method for Assaying Antibiotic Substances. Industrial and engineering chemistry. Analytical Edition. 17 (9): 556-558.

[49] Cortese, F, J. M. Mcguire, and T. V. Pagxe. 1949. Some New Procedures and Instruments Useful for Microbiological Antibiotic Testing by Diffusion Methods. I. A New Zone Reader. Journal of the American Pharmaceutical Association. 88(18): 459-462.

[50] Masuyaia, M. 1949. On a One-Dimensional Diffusion Method of Assaying Antibiotic Substances and Its Fundamental Formulas. Biometrics. 5(4): 317-329.

[51] Florey, H. W., E. Chain, N. G. Heatley, M. A. Jenings, A. G. Sanders, E. P. Abraham and M. E. Florey, 1950. Antibiotics: a Survey of
Penicillin, Streptomycin and Other Antimicrobial Substances from Fungi, Actinomycetes, Bacteria and Plants. The Journal of the American Medical Association. 143(13): 1217.

[52] Miyatura, S. 1951. On the Influence of Ph of Sample on the Cup Assay of Antibiotics. Journal of Antibiotics [Japan] 4: 290-295.

[53] Ehrlich, J., W. P. Iverson. and A. Kohberger. 1951. Agar Diffusion Methods for the Assay of Viomycin. Journal of Antibiotics \& Chemotherapy. 1: 211-216.

[54] Eisman, P. C., R. L. Mayer, K. Aronson and W. S. Marsh. 1946. Resistant Microorganisms and Their Use for the Classification of Antibacterial Substances. Journal of Bacteriology. 52: 501-502.

[55] Eisenian, W. and C. E. Bricker. 1949. Spectrophotometric method for Determining Streptomycin. Analytical Chemistry. 21(12): 1507-1508.

[56] Eiery, W. B. and A. D. Walker. 1949. Colorimetric Determination of Streptomycin B (Mannosidostreptomycin). Analyst. 74: 455-457.

[57] Gavin, J. 1957a. Microbiological Process Report. Analytical Microbiology. III. Turbidimetric Methods. Applied Microbiology. 5(4) 235-243.

[58] Simon, J.S. and E.J. Yin. 1970. Microbioassay of Antimicrobial. Applied Microbiology. 19(4): 573-579.

[59] Gavin, J. 1957b. Microbiological Process Report. Analytical Microbiology. II. The Diffusion Methods. Applied of Microbiology. 5(1): 25-33.

[60] Niedermayer, A. O., F. M. Russo-Alesi, C. A. Lendzian and J. M. Kelly. 1960. Automated System for the Continuous Determination of Penicillin in Fermentation Media Using Hydroxylaminereagent. Analytical Chemistry. 32(6):664-666.

[61] Kuzel, N. R. and F. W. Kavanaugh. 1971. Automated System for Microbiology. It Construction of System and Evaluation of Antibiotics and Vitamins. Journal of Pharmaceutical Sciences. 60(4): 767-773.

[62] White A. R, C. Kaye, J. Poupard, R. Pypstra, G. Woodnutt and B. Wynne. 2004. Augmentin® (amoxicillin/clavulanate) In Treatment of Community-acquired Respiratory Tract Infection: A Review of the Continuing Development of an Innovative Antimicrobial Agent. Journal of Antimicrobial Chemotherapy. 53(S1): i3-i20

[63] Witte, W. 1998. Medical Consequences of Antibiotic Use in Agriculture. Science. 279(5353): 996-997. 